\title{
Study of Forces Influencing the Shaking Parameters in Mechanized / Robot-assisted Harvesting of Olives
}

\author{
Theoharis Babanatsas ${ }^{1, *}$, Dan Ovidiu Glavan ${ }^{1}$, Roxana Mihaela Babanatis Merce ${ }^{1}$, and \\ Andreea Ioana Glavan ${ }^{2}$ \\ ${ }^{1}$ Faculty of Engineering, University "Aurel Vlaicu” of Arad, 310130 Arad, Romania \\ ${ }^{2}$ Faculty of Science and Engineering Computing Science, University of Groningen
}

\begin{abstract}
In this paper, we carried out a study of the parameters influencing the separation of olives from tree branches when harvesting is executed by means of shaking the trunk. It showed there are two important parameters, namely the shaking force and the amplitude of the shaking [1, $2,3]$. In order to determine these two parameters, we used a mathematic model which was used in developing a software that can determine their value depending on the diameter of the trunk in the contact area [4].
\end{abstract}

\section{Theoretical consideration}

It is known from the theory that the vibrations at the contact point of the olive with the shaking device is one of the most important elements influencing the detachment of the olives, and from this point of view it is useful to change the parameters such as the fecundity and amplitude for a detachment/harvest as efficient as possible [1-3]. It is necessary to know the parameters that influence the transmission of the vibrations from the initial point to the prophesized olive. It's possible the power and the value of amplitude to be variable? What about if these characteristics may be correlated with olive diameter [4].

\section{Experimental conditions}

In this study we developed a mathematical formula that is variable and is based on trunk thickness [5]. This study helps us to understand the vibration harvesting phenomenon as well as designing the most efficient devices and the best vibration methods, all for more efficient harvesting.

Thus, we started from the hypothesis to simplify the structure of the olive tree, namely in the trunk dimensions and the dimensions of the main branches, figure 1.

\footnotetext{
* Corresponding author: babanatsas@,outlook.ro
} 


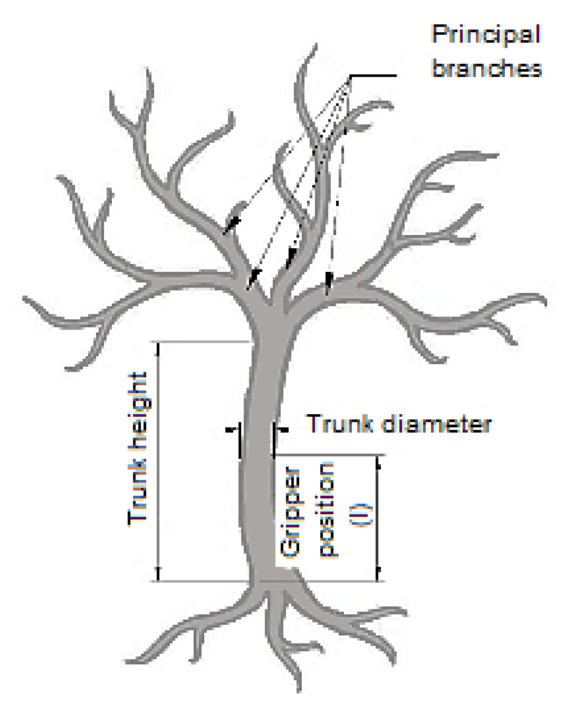

Fig. 1. Olive tree structure

The theory of wood vibration study is very complex due to the morphology and the characteristics of the wood [6]. That is why we took the modulus of elasticity of the longitudinal of olive tree as the modulus of overall elasticity of olive wood. Also, external influences, namely air resistance to the movements of branches, leaves, and olives must also be taken into account [7]. These characteristics determined the olive trunk to the point of vibration as a recessed bar figure 2 .

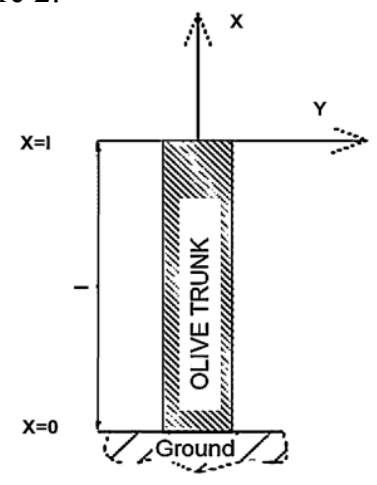

Fig. 2. Simplification of the olive trunk in the shape of a variable section bar.

The vibration transmission equation is given by [8]:

Where:

$$
\sigma=\mathrm{E} \cdot \varepsilon+\mathrm{c} \cdot \dot{\varepsilon}
$$

$\sigma-$ surface tension

E - modulus of elasticity

$\mathrm{c}-$ internal damping coefficient

$\varepsilon-$ deformation

$\dot{\varepsilon}=\frac{\mathrm{d} \varepsilon}{\mathrm{dt}}$

$\mathrm{k}-$ coefficient of elasticity 
The Kelvin-Voigt and Maxwell, figure 3, models give mathematical models for the above equation [9-10].

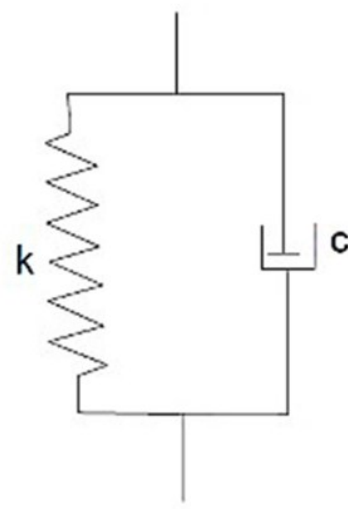

a)

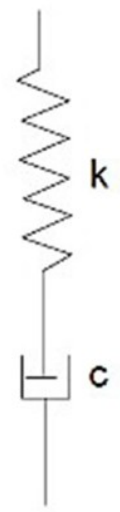

b)

Fig. 3. Kelvin-Voigt (a) and Maxwell (b) models

Researchers have shown that the Maxwell model is closest to the behavior of olive wood, the vibration transmission equation becomes:

$$
\epsilon=\frac{\sigma}{E}+\frac{1}{c} \int_{-\infty}^{t} \sigma d t
$$

Logarithmic damping $(\delta)$, for the olive tree given by the equation:

$$
\delta=\frac{E}{2 \omega c}
$$

This equation shows that damping is inversely proportional to frequency.

The equation of transmitting vibrations to the olive trunk can be defined as being:

Where:

$$
\rho \frac{\partial^{2} y}{\partial t^{2}}+E \frac{\partial^{4} y}{\partial t^{4}}+C \frac{\partial^{5} y}{\partial x^{4} \partial t}=0
$$

$\rho-$ density

$\mathrm{t}-$ time

In the above equation we still need to add the strength of air resistance to the branches, leaves and olives.

The strength of the air resistance is given by the equation:

Where:

$$
\mathrm{F}_{\mathrm{d}}=\frac{\mathrm{C}_{\mathrm{d}} A \mathrm{AV}^{2}}{2}
$$

$C_{d}$ - coefficient of resistance

$A-$ section of the contact surface

$V$ - speed of movement

$p$ - air density

Simplifying the equation, the energy explored by linear depreciation will be:

$$
W=C_{v} V_{m}^{2} \frac{\tau}{\varpi}
$$


Where:

$C_{v}$ - linear depreciation coefficient

At aerodynamic depreciation, the energy that depreciates on whatever period it is:

Where:

$$
W=\frac{8}{3} C_{d} \frac{V_{m}^{3}}{\varpi}
$$

$\mathrm{C}_{\mathrm{d}}-$ coefficient of aerodynamic depreciation

$$
\begin{gathered}
C_{v}=\frac{8}{3 \pi} C_{d} V_{m} \\
C_{v} \frac{\partial y}{\partial t}
\end{gathered}
$$
form:

Thus, the vibration equation with internal and external depreciation will take that

$$
\rho \frac{\partial^{2} y}{\partial t^{2}}+E \frac{\partial^{4} y}{\partial t^{4}}+C \frac{\partial^{5} y}{\partial x^{4} \partial t}+C_{v} \frac{\partial y}{\partial t}=0
$$

The final equation of vibration will be:

$$
y(x, t)=F_{x}\left[I \cos \lambda_{x}+I I \sin \lambda_{x}+\left((1-I) \operatorname{ch} \lambda_{x}-I I \operatorname{sh} \lambda_{x}\right)\right] e^{\omega}
$$

Where:

$F_{x}-$ The force required to generate the frequency over the length of $l$ at the pointx ( $x$ $\in 0,1)$

$\mathrm{I}, \mathrm{II}-$ Constants defining the initial conditions on $\mathrm{x}$ and $\mathrm{y}$ axes

$$
\begin{array}{r}
I=\frac{\cos \lambda_{1} \operatorname{ch} \lambda_{1}-\sin \lambda_{1} \operatorname{sh} \lambda_{1}+1}{2\left(1+\cos \lambda_{1} \operatorname{ch} \lambda_{1}\right)} \\
I I=\frac{\cos \lambda_{1} \operatorname{sh} \lambda_{1}-\sin \lambda_{1} \operatorname{ch} \lambda_{1}+1}{2\left(1+\cos \lambda_{1} \operatorname{ch} \lambda_{1}\right)}
\end{array}
$$

$\lambda_{\mathrm{l}}$ - overall damping coefficient

$\mathrm{a}-$ damping coefficient on the $\mathrm{x}$ axis

$\mathrm{b}-$ damping coefficient on $\mathrm{y}-$ axis

$$
\begin{gathered}
\lambda^{4}=\frac{\mathrm{b}^{2}}{\mathrm{a}^{2}} \\
\mathrm{a}^{2}=\mathrm{E}+\omega \mathrm{CI} \\
\mathrm{b}^{2}=\omega \mathrm{C}_{\mathrm{v}}-\omega^{2} \varrho
\end{gathered}
$$

Correction coefficient: 


$$
\begin{aligned}
& c r=\left[\frac{\cos \lambda_{1} \operatorname{ch} \lambda_{1}-\sin \lambda_{1} \operatorname{sh} \lambda_{1}+1}{2\left(1+\cos \lambda_{1} \operatorname{ch} \lambda_{1}\right)} \cos \lambda_{x}\right. \\
& +\frac{\cos \lambda_{1} \operatorname{sh} \lambda_{1}-\sin \lambda_{1} \operatorname{ch} \lambda_{1}+1}{2\left(1+\cos \lambda_{1} \operatorname{ch} \lambda_{1}\right)} \sin \lambda_{x} \\
& +\left(\left(1-\frac{\cos \lambda_{1} \operatorname{ch} \lambda_{1}-\sin \lambda_{1} \operatorname{sh} \lambda_{1}+1}{2\left(1+\cos \lambda_{1} \operatorname{ch} \lambda_{1}\right)}\right) \operatorname{ch} \lambda_{x}\right. \\
& \left.\left.-\frac{\cos \lambda_{1} \operatorname{sh} \lambda_{1}-\sin \lambda_{1} \operatorname{ch} \lambda_{1}+1}{2\left(1+\cos \lambda_{1} \operatorname{ch} \lambda_{1}\right)} \operatorname{sh} \lambda_{x}\right)\right] e^{\omega}
\end{aligned}
$$

The equation of power required for vibration is:

$$
P_{l}=\frac{6 * E *{\frac{\pi * D^{4}}{64}}_{24}^{2 l^{3}} * A}{4} * c r
$$

Where:

E modulus of elasticity at olive tree $\mathrm{E}=\mathbf{1 7 . 7 7 0} \mathrm{N} / \mathrm{mm}^{2}[6,7]$

$\mathrm{M}$ Rupture module on the olive tree $\mathrm{M}=\mathbf{1 5 5 . 4 4 0} \mathrm{N} / \mathbf{m m}^{2}[6,7]$

$1=500 \mathrm{~mm}$

cr- Correction module, $c r=0.9784346$

D - Diameter $D \in[50,500] \mathrm{mm}$

A - Amplitude $A \in[5,150] \mathrm{mm}$

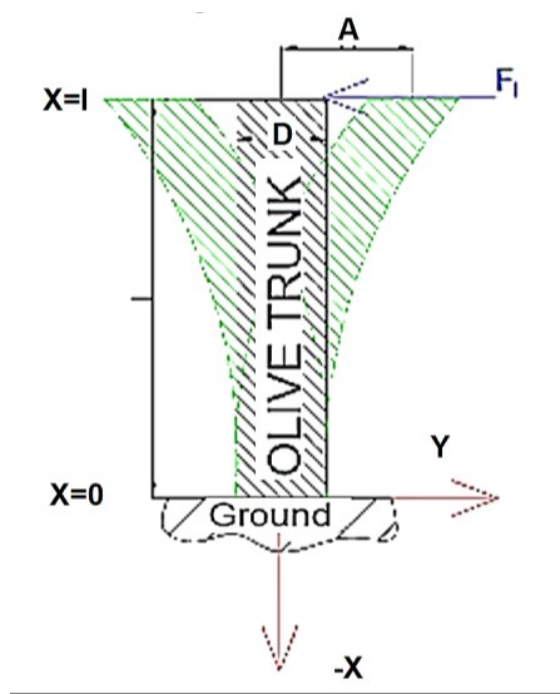

Fig. 4. Simplified scheme of the olive trunk at the moment of vibration

From previous experimental data [1-2], from empirical data [3, 7] and from equation (18), we create a calculation database (figure 5) which, based on olive tree diameter (D) and will calculate the optimal amplitude value (A) and the required vibration power (F1) [1-3, 11-12]. 


\begin{tabular}{|c|c|c|c|c|c|c|}
\hline$\angle$ & A & B & C & D & $E$ & $\mathrm{~F}$ \\
\hline 1 & $\begin{array}{c}\text { D- Diameter } \\
(\mathrm{mm}) 50 . .500 \mathrm{~mm}\end{array}$ & $\begin{array}{l}\text { A- Amplitude } \\
(\mathrm{mm}) \max \\
15 \mathrm{~mm}\end{array}$ & $\begin{array}{l}\text { I- high (mm) } \\
500 \mathrm{~mm}\end{array}$ & $\begin{array}{c}\text { E-module of } \\
\text { elasticity } 17.770 \\
\mathrm{~N} / \mathrm{mm}^{2}\end{array}$ & $6^{\star} E^{\star} \ldots$ & Power \\
\hline 2 & 50 & 153.846 & 500 & 17.77 & $5,032,400,972.44$ & $125,810,024.31$ \\
\hline 3 & 100 & 76.923 & 500 & 17.77 & $40,259,207,779.54$ & $16,103,683,111.81$ \\
\hline 4 & 150 & 51.282 & 500 & 17.77 & $135,874,826,255.94$ & $275,146,523,168.27$ \\
\hline 5 & 200 & 5.000 & 500 & 17.77 & $41,869,576,090.72$ & $267,965,286,980.60$ \\
\hline 6 & 250 & 36.364 & 500 & 17.77 & $743,422,870,928.94$ & $11,615,982,358,264.70$ \\
\hline 7 & 300 & 30.303 & 500 & 17.77 & $1,284,634,720,965.21$ & $41,622,164,959,272.80$ \\
\hline 8 & 350 & 25.974 & 500 & 17.77 & $2,039,952,357,829.01$ & $122,448,140,278,687.00$ \\
\hline 9 & 400 & 22.727 & 500 & 17.77 & $3,045,060,079,324.94$ & $311,814,152,122,874.00$ \\
\hline 0 & 450 & 20.202 & 500 & 17.77 & $4,335,642,183,257.58$ & $711,153,709,108,825.00$ \\
\hline 1 & 500 & 18.182 & 500 & 17.77 & $5,947,382,967,431.53$ & $1,486,845,741,857,880.00$ \\
\hline \multicolumn{7}{|r|}{ 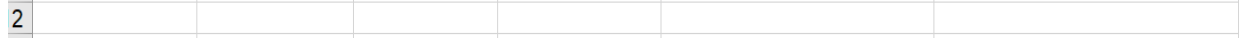 } \\
\hline \multicolumn{7}{|l|}{3} \\
\hline \multicolumn{7}{|c|}{4} \\
\hline \multicolumn{3}{|c|}{$5 \mathrm{IF}(\mathrm{A} 2=200,5, \mathrm{IF}(\mathrm{A} 2>200,3,7))$} & & & \multicolumn{2}{|c|}{$\mathrm{IF}(\mathrm{A} 2=200,5, \mathrm{IF}(\mathrm{A} 2>200,3,7))$} \\
\hline 6 & \multicolumn{4}{|c|}{$\operatorname{IF}(A 2=200,5, \operatorname{IF}(\mathrm{A} 2>200,1000 /(\mathrm{A} 2 * 1.1), 1000 /(\mathrm{A} 2 * 1.3)))$} & \multicolumn{2}{|c|}{$\mathrm{IF}(\mathrm{A} 2=200,5, \mathrm{IF}(\mathrm{A} 2>200,1000 /(\mathrm{A} 2 * 1.1), 1000 /(\mathrm{A} 2 * 1.3)))$} \\
\hline 7 & \multicolumn{4}{|c|}{$\mathrm{IF}\left(\mathrm{A} 2=200,5, \mathrm{IF}\left(\mathrm{A} 2>200,1000 / \mathrm{A} 2^{*} 0.7,1000 / \mathrm{A} 2^{\star} 1.3\right)\right)$} & \multicolumn{2}{|c|}{$\mathrm{IF}\left(\mathrm{A} 22=0.200,0.05, \mathrm{IF}\left(\mathrm{A} 2>0.200,1000 / \mathrm{A} 22^{*} 1.1,1000 / \mathrm{A} 22^{*} 1.3\right)\right)$} \\
\hline 8 & & & & & & \\
\hline
\end{tabular}

Fig. 5. Amplitude and power data base required for vibration depending on olive tree diameter

\section{Results and discussions}

From calculations are obtained an optimal amplitude and shaking power. Our tests indicate a variation between amplitude and shaking forces. When the olive tree diameter is bigger, the amplitude value is smaller but the shaking force is higher and when the olive tree diameter is smaller the amplitude value is higher but the shaking force is lower, (figures 6 and 7).

Amplitude variation according to olive diameter

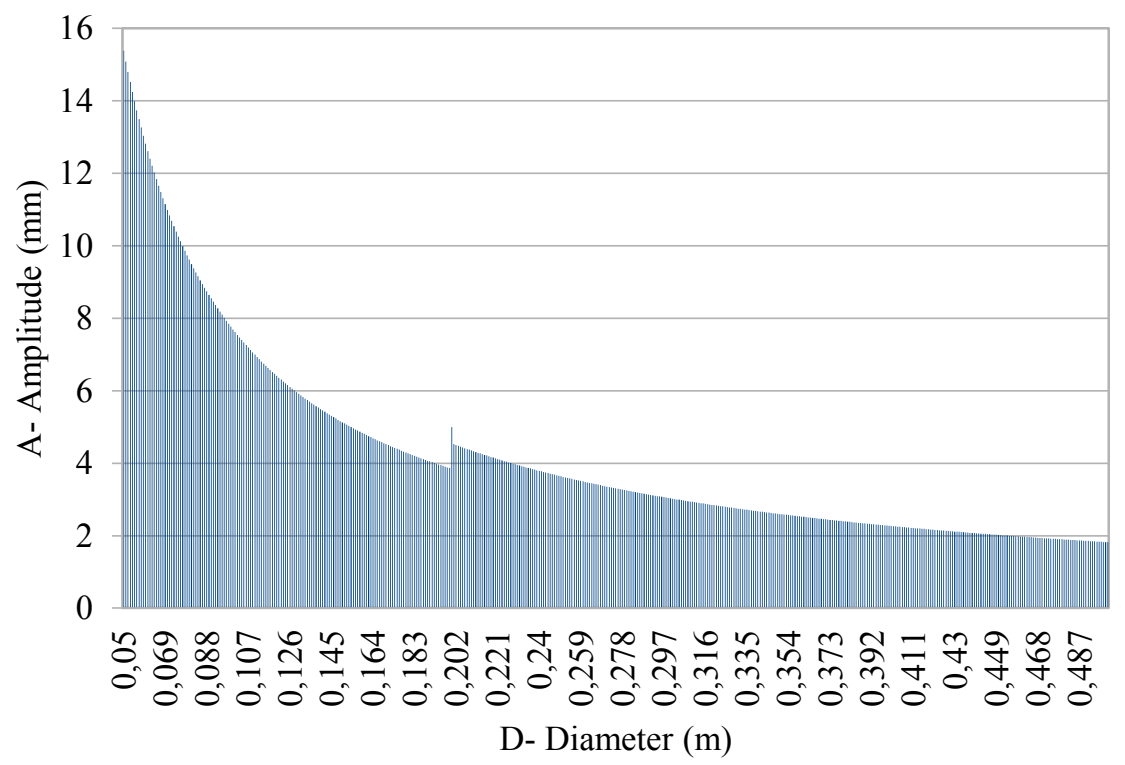

Fig. 6. Amplitude variation according to olive diameter 
Power according to diameter

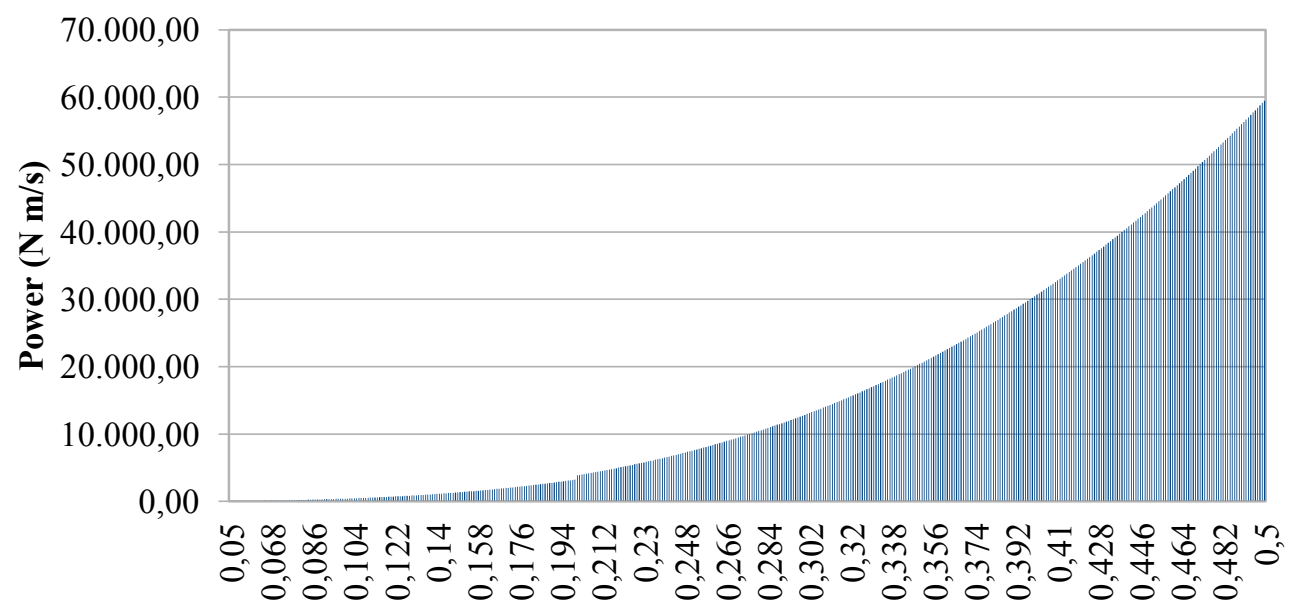

Diameter (m)

Fig. 7. Power variation according to olive diameter

These values were taken in consideration for an experimental study of decreasing the damage to the olive tree during mechanized harvesting part of another research paper [4].

\section{Conclusions}

Our program is based on empirical values and values obtained from experimental tests. Moreover, the purpose of this work is to create a program that will provide us with optimal harvesting parameters so as not to damage the olive tree and harvesting to be effective. Values obtained from the program indicate an influence of the olive diameter on the harvest parameters.

\section{References}

1. D.O. Glavan, T. Babanatsas and R.M. Babanatis Merce, IOP Conference Series: 8th International Conference on Manufacturing Science and Education - MSE 2017, Sibiu 121 (2017)

2. T. Babanatsas, D. O. Glavan, R. M. Babanatis Merce and S. Maris, IOP Conference Series: Materials Science and Engineering, International Conference on Applied Sciences, Hunedoara, Romania, 294 (2018)

3. M.Z. El Attar, M.N. El Awady, M. Rashwan and M.A.I. Genaidy, 10th MSAE conf. (2004)

4. T. Babanatsas, R. M. Babanatis Merce, D. O. Glavan and A. Komjaty, Acta Technica Napocensis, Series: Applied Mathematics, Mechanics and Engineering, 62, Issue I (2019)

5. Debojit, Biswas Jain Hitesh, K. Arora Manoj and R. Balasubramanian, International Journal of Earth Sciences and Engineering, 04, No 06 SPL (2011)

6. D. Birbili, Wood properties (Ed. TEI, 2012)

7. Ministry of Agriculture of Greece. Cultivation of the olive (Ed. A.S. Print Xpress Ltd, 2013)

8. D. Mnerie, D. Tucu, A. Golimba and G. Anghel, Actual tasks on agricultural engineering, proceedings. Book Series: Actual Tasks on Agricultural Engineering-Zagreb, 36, 617 (2008)

9. D. Tucu, Actual tasks on agricultural engineering, proceedings. Book Series: Actual Tasks on Agricultural Engineering-Zagreb, 39, 171 (2011)

10. I. Radu and D. O. Glavan, Elemente de vibraţii mecanice, 64-78 (Ed. „UAV” Arad, 2001) 
11. C. Peri, The extra virgin Olive Oil Handbook. Wiley-Blackwell, Italy (2014)

12. D. Tucu, Proceedings of the 40th International Symposium "Actual tasks on agricultural engineering”, Opatija, Croatia, 549, 40 (2012) 